\title{
UMA ANÁLISE DAS CAPACIDADES TECNOLÓGICAS DA AGROINDÚSTRIA CANAVIEIRA EM MINAS GERAIS ${ }^{1}$
}

\author{
Pery Francisco Assis Shikida ${ }^{2}$ \\ Paulo Furquim de Azevedo \\ Carlos Eduardo de Freitas Vian ${ }^{4}$
}

\begin{abstract}
Resumo: Este trabalho procurou verificar quais são as capacidades tecnológicas da agroindústria canavieira em Minas Gerais, que possui a segunda maior área plantada de cana-de-açúcar no Brasil, ou seja, 679 mil hectares. Para contemplar este escopo foram coletados dados primários junto às usinas/destilarias, mediante aplicação de questionários. O referencial teórico utilizado foi o da matriz de capacidades tecnológicas, que é balizado em Lall (1992), sendo esta matriz dividida em três especificações: básica (simple routine), intermediária (adaptive duplicative) e avançada (innovative risky). Como corolário, esta agroindústria canavieira, tecnicamente qualificada e com baixos custos, apresenta um razoável domínio das capacidades tecnológicas básica e intermediária. No entanto, as capacidades tecnológicas avançadas ainda estão atrasadas em relação à fronteira tecnológica.
\end{abstract}

Palavras-chave: Dinâmica, tecnologia, açúcar, álcool.

\footnotetext{
Recebido em: 17/03/2010; Aceito em: 02/07/2010. Os autores agradecem ao assessor econômico Mário Campos (SIAMIG/SINDAÇÚCAR-MG), pela contribuição na aplicação e coleta dos questionários, e aos pareceristas desta Revista, pelas sugestões e comentários.

2 Pós-doutor em Economia pela FGV-SP. Professor Associado da Universidade Estadual do Oeste do Paraná Professor do Programa de Mestrado em Economia Regional da UEL. E-mail: peryshikida@ hotmail.com

3 Doutor em Economia pela FEA-USP. Professor Adjunto da Fundação Getúlio Vargas - São Paulo. Bolsista de Produtividade de Pesquisa (CNPq). E-mail: paulo.azevedo@fgv.br

4 Doutor em Economia pela UNICAMP. Professor Doutor da ESALQ/USP. Coordenador do Grupo de Extensão e Pesquisa em História da Agricultura e dos Complexos Agroindustriais (GEPHAC). E-mail: cefvian@esalq.usp.br
} 


\section{Introdução}

É incontestável a importância econômica da agroindústria canavieira brasileira, seja na geração de renda e emprego ou na de divisas, derivada da elevada competitividade desse sistema no Brasil. Menos passíveis de acordo, entretanto, são as bases sobre as quais se assenta esta competitividade, se predominantemente na exploração de vantagens derivadas de recursos naturais, se nas condições de oferta de mão de obra, ou, calcada em capacidades tecnológicas, que permitem a elevação da produtividade dos fatores ou o desenvolvimento de novos produtos. Esse conceito é derivado de Lall (1992), sendo sua matriz conceitual dividida em três especificações: básica (simple routine), intermediária (adaptive duplicative) e avançada (innovative risky). Para tanto, tornase necessário, por exemplo, avaliar as capacidades tecnológicas dessa indústria, de modo a contribuir para a melhor caracterização das bases de sua competitividade. E, isso pode ser feito focando, também, alguns estados relevantes nesse cenário, mas que são relativamente pouco estudados (SOUZA et al., 2005).

Desse modo, este trabalho tem por objetivo investigar as capacidades tecnológicas da agroindústria canavieira em Minas Gerais, que representa $7,5 \%$ da produção de cana-de-açúcar, $7,1 \%$ da produção de açúcar e 7,9\% da produção de álcool total do país (dados da safra 2008/2009), sendo a terceira força estadual nesse segmento, mas que tende a superar o segundo estado em termos de importância produtiva na agroindústria canavieira do país, o Paraná. De acordo com dados da Companhia Nacional de Abastecimento (CONAB) 2010, a produção mineira de canade-açúcar destinada à indústria sucroalcooleira, em 2010, deverá atingir 56,2 milhões de toneladas, superando a produção obtida na safra 2008/ 2009, que foi de 42,5 milhões de toneladas. São Paulo é o destaque ímpar, sendo responsável por $60,9 \%, 63,3 \%$ e $60,8 \%$ das produções nacionais de cana, açúcar e álcool total, respectivamente. 
Este artigo encontra-se dividido em seis seções. Na seguinte, é apresentada uma síntese da caracterização da agroindústria canavieira. $\mathrm{Na}$ terceira seção, o referencial teórico que norteia a presente pesquisa - matriz de capacidades tecnológicas de Lall (1992). O referencial analítico é exposto na quarta seção, enquanto os resultados e discussão compreendem a quinta seção. Por fim, na sexta seção, apresentam-se as considerações finais.

\subsection{Caracterização da agroindústria canavieira}

O Brasil configura-se como o maior produtor mundial de cana-de-açúcar e açúcar, tendo produzido, na safra 2008/2009, 569 milhões de toneladas de cana-de-açúcar, 31 milhões de toneladas de açúcar e 27,5 milhões de $\mathrm{m}^{3}$ de álcool. Em relação ao comércio exterior, o país é um dos principais fornecedores mundiais, tendo exportado, em 2008, aproximadamente 20 milhões de toneladas de açúcar e 5 milhões de $\mathrm{m}^{3}$ de álcool etílico, representando, respectivamente, $62,8 \%$ e $22,8 \%$ da oferta doméstica. A lavoura da cana-de-açúcar ocupa cerca de 7 milhões de hectares, ou seja, aproximadamente $2 \%$ de toda a terra arável do país e, em função de suas especificidades geográficas e edafo-climáticas, são permitidas duas safras por ano (uma no Norte-Nordeste e outra no Centro-Sul), possibilitando a produção de açúcar e álcool para os mercados interno e externo durante o ano todo [União da Indústria de Cana-de-Açúcar (UNICA)].

Por outro lado, o avanço da pesquisa e a difusão de novas variedades de cana, além dos avanços na gestão industrial, têm possibilitado o aumento do tempo de safra no Centro-Sul, para, aproximadamente, nove meses ou mais. Na safra 2008/2009, algumas usinas paulistas trabalharam ininterruptamente, emendando uma safra na outra. Isso foi ocasionado, predominantemente, por condições de mercado, mas não descarta a possibilidade dessa prática tornar-se comum no futuro. 
Segundo Souza e Macedo (2010) e Schmidtke et al. (2008), o momento da agroindústria canavieira brasileira é de elevado dinamismo devido a uma junção de fatores favoráveis: a) maior estabilidade da economia nacional, com alguns aspectos macroeconômicos, como controle fiscal e regime de metas para a inflação denotando maior maturidade à política econômica do país; b) cenário benéfico para a commodity açúcar, dada a competitividade do açúcar brasileiro e as expectativas de possível diminuição do protecionismo no comércio internacional; c) renovado interesse pelo álcool combustível, haja vista a bem sucedida introdução no mercado automobilístico dos veículos flex fuel e as elevações dos preços internacionais do petróleo; d) crescente preocupação ambiental, resultando no aumento da demanda por álcool como fonte de energia, pois auxilia na redução das emissões de gases do efeito estufa. A pressão mundial, em favor de combustíveis ecologicamente mais adequados, está contribuindo para que os Estados Unidos se posicionem a favor da preservação ambiental. Esse país não assinou o Protocolo de Kyoto (Tratado Internacional que estipula compromissos mais rígidos para a redução da emissão dos gases que provocam o efeito estufa).

Durante o período de 1990 até 2009, evidencia-se um cenário de readaptação da agroindústria canavieira sob o amparo da desregulamentação setorial, em que os produtores tiveram que se adaptar ao livre mercado sem os incentivos, subsídios e coordenação estatais (VIAN, 2003). Nesse período, o preço do açúcar no mercado interno deixou de ser tabelado. A partir de 1994, as exportações do açúcar foram liberadas; em 1997, o preço do álcool anidro deixou de ser regulado; em 1998, o Governo liberou o preço da cana-de-açúcar, e, em 1999, o preço do álcool hidratado também deixou de ser tabelado (ALVES, 2002).

Nesse sentido, os produtores passaram a desenvolver novas competências visando aumentar cada vez mais sua eficiência técnica, modernizando a estrutura organizacional das firmas e buscando outros mecanismos de coordenação corporatista, por exemplo, na UNICA, em São Paulo; na Associação de Produtores de Bioenergia do Estado do Paraná (ALCOPAR), no Sindicato da Indústria de Fabricação do Álcool no 
Pery Francisco Assis Shikida, Paulo Furquim de Azevedo \&

Carlos Eduardo de Freitas Vian

Estado de Minas Gerais (Siamig) ou no Sindicato da Indústria do Açúcar no Estado de Minas Gerais (Sindaçúcar-MG). O paradigma tecnológico tornou-se, agora, condição sine qua non para a sobrevivência no mercado. Ressalta-se que a demanda pelo álcool está sendo impulsionada pelo crescimento das vendas de veículos flex fuel [em 2008, as vendas de carros flex fuel chegaram a 87,2\% do total (UNICA, 2010)] e pelo aumento de sua exportação (antes periférica ao açúcar). Os patamares dos preços do petróleo, mesmo oscilando frente às euforias das crises internacionais, continuam favoráveis ao dinamismo setorial da agroindústria canavieira, visto que o álcool é competitivo com o petróleo custando acima de US\$30 o barril (PAULILLO et al., 2007).

A UNICA (2007) estima que "[...] em 2012/13 o setor sucroalcooleiro esteja processando aproximadamente 700 milhões de toneladas de cana, produzindo 36 bilhões de litros de álcool e 39 milhões de toneladas de açúcar [...]", o que representa um crescimento referente aos dados da safra 2008/2009 de 23\%, 31\%, 26\% em relação à cana, ao álcool e ao açúcar, respectivamente, buscando atender à demanda doméstica e uma parcela da externa.

Em termos regionais, o estado foco desta pesquisa, Minas Gerais, tem a cana-de-açúcar como um dos seus principais produtos agrícola, ocupando uma área de 679 mil hectares. A produção apresenta maior concentração no Triângulo Mineiro (responsável por aproximadamente $65 \%$ de toda a produção estadual), pois é a região que reúne condições de solo e clima favoráveis, e, ainda, possui infraestrutura de armazenamento e logística, facilitando o escoamento da produção até o porto de Santos. Minas Gerais conta com 40 unidades produtoras de açúcar e/ou álcool (9\% do total do país, superado apenas por São Paulo, com 199 unidades, ou 48\% do total do país) que atingem economicamente 86 dos 853 municípios mineiros, gerando aproximadamente 130 mil empregos diretos - dados compilados de Hersen et al. (2008) e Siamig/Sindaçúcar (2009).

Para Goes et al. (2008), nos próximos anos a expansão da área plantada com cana no país será decorrente basicamente do aumento da demanda por etanol e da melhoria da rentabilidade do setor provocada pelos avanços 
tecnológicos resultantes de novos projetos, em que se destacam os estados de Minas Gerais, Paraná e São Paulo, juntamente com Goiás e Mato Grosso do Sul. Nesse sentido, torna-se importante o estudo das realidades estaduais fortes no segmento, justificando-se esta pesquisa sobre quais são as capacidades tecnológicas da agroindústria canavieira em Minas Gerais.

\section{Referencial Teórico}

Esta seção reúne elementos necessários para evidenciar a dimensão dinâmica das firmas que buscam, por meio de capacidades tecnológicas, uma vantagem competitiva singular no mercado em que está inserida. Esse quadro intrinsecamente dinâmico tem feito com que a busca por tecnologias superiores - e sua consequente aplicação -, seja o elementochave para uma melhor inserção da firma no mercado.

A esse respeito, Matesco (1994) afirma que:

[...] a tecnologia é um elemento de destaque entre os fatores concorrenciais das empresas produtivas modernas. As empresas alocam recursos em alguma fonte de obtenção de tecnologia, como forma de criar constantemente novos e melhorados produtos e processos de produção e, assim, aumentar a sua competitividade em seu mercado de atuação ou melhorar a capacitação para penetrar em novos mercados (MATESCO, 1994, p.397).

Entretanto, por qual sentido este trabalho envereda em termos do uso de tecnologia? Schumpeter (1961) deu uma nova concepção ao estudo da dinâmica econômica ao enfatizar o papel das inovações no sistema econômico. Para esse autor, o elemento motriz da evolução do capitalismo 
Pery Francisco Assis Shikida, Paulo Furquim de Azevedo \&

Carlos Eduardo de Freitas Vian

é a inovação, na forma de introdução de novos bens ou técnicas de produção, do surgimento de novas fontes de oferta de matérias-prima, de novos mercados ou de composições industriais. Isso significa que a constituição de capacidades tecnológicas - fundamento para a inovação -, passou a ser considerada uma variável endógena ao processo de desenvolvimento econômico, sendo a dinâmica tecnológica o motor do desenvolvimento das economias capitalistas. Para tanto, este trabalho toma como referência Lall (1992), tendo como principal motivação o fato da competitividade de uma firma poder ser traduzida como um conjunto de suas competências, aqui denominada capacidades tecnológicas, que serão descritas à frente.

Tecnologia pode ser classificada como um conjunto de partes do conhecimento, teórico ou prático, que adquire especificidade ao assumir formas de aplicação em uma determinada atividade (DOSI, 1984). Tal conjunto envolve desde métodos, experiências, procedimentos e knowhow, até mecanismos e equipamentos. Dosi e Coriat (2002) colocaram as estratégias de aprimoramento das competências como fator substancial para o entendimento da relação da empresa com o seu ambiente competitivo, o que perpassa pela criação e difusão da tecnologia.

De modo complementar, Tigre (2005) chama a atenção para o fato das tecnologias poderem ser " [...] consideradas idiossincráticas ao tipo de indústria e à natureza dinâmica das configurações particulares que condicionam o processo competitivo". Portanto, torna-se necessário destacar a questão da dinâmica tecnológica inserida no locus da concorrência, isto é, no eixo firma-mercado, em que a firma (ou indústria) é vista, dinamicamente, como de base técnica mutável, cada vez mais influenciada por inovações, introduzidas mediante decisões empresariais estratégicas, que se baseiam nas condições de seleção e de apropriabilidade da inovação sob a forma de lucros e com a presença não eliminável de incerteza nessas decisões (POSSAS, 1991). 
A competitividade pode ser definida em, pelo menos, três níveis de análise: empresas, setores industriais e sistemas produtivos, nesse caso incluindo todos os elos da cadeia produtiva. Em sua primeira dimensão, "[...] a competitividade é definida como a capacidade de a empresa formular e implementar estratégias concorrenciais, que lhe permita ampliar ou conservar, de forma duradoura, uma posição sustentável no mercado" (KUPFER, 1996, p.367). Assim sendo, “[...] a competitividade depende da criação e renovação das vantagens competitivas por parte das empresas em consonância com os padrões de concorrência vigentes, idiossincráticos de cada setor da estrutura produtiva" (HAGUENAUER et al., 1996, p.196). Por isso, a importância da avaliação de capacidades tecnológicas para a compreensão da competitividade das firmas.

Nesse contexto, para analisar a dinâmica tecnológica da agroindústria canavieira de Minas Gerais, este trabalho remete ao conceito de capacidades tecnológicas, posto que as vantagens competitivas das firmas perpassam pela criação e renovação das capacidades de adquirir, usar, adaptar ou criar tecnologia, seja no âmbito do investimento, operação/ produção, inovação ou nas relações com a economia (DAHLMAN et al., 1985, apud CANUTO, 1991).

De acordo com Lall (1992), além da capacidade de adquirir, assimilar, usar, adaptar, mudar ou criar tecnologia, as capacidades tecnológicas das empresas podem ser traduzidas como a capacidade de uso e geração de inovações, podendo ser dividida em três níveis distintos: básica, intermediária e avançada, conforme a Figura 1. 
Pery Francisco Assis Shikida, Paulo Furquim de Azevedo \&

Carlos Eduardo de Freitas Vian

\begin{tabular}{|c|c|c|c|c|}
\hline \multirow{2}{*}{ Âmbitos } & \multirow{2}{*}{ Perfis } & \multicolumn{3}{|c|}{ Capacidade Tecnológica - principais condicionantes e sua gradação } \\
\hline & & Básica & Intermediária & Avançada \\
\hline \multirow[b]{2}{*}{ Investimento } & Inicial & $\begin{array}{l}\text { Estudos de viabilidade técrico- } \\
\text { econômica; seleção do local; } \\
\text { cronograma de investimentos }\end{array}$ & $\begin{array}{l}\text { Negociação de contratos com } \\
\text { fornecedores (condições } \\
\text { satisfatórias); sistemas de } \\
\text { informação }\end{array}$ & - \\
\hline & $\begin{array}{l}\text { Execução de } \\
\text { projetos }\end{array}$ & Construção de plantas & $\begin{array}{l}\text { Seleção do melhor fornecedor } \\
\text { de equipamentos; } \\
\text { recrutamento e treinamento de } \\
\text { pessoal qualificado; } \\
\text { engenharia detalhada }\end{array}$ & $\begin{array}{l}\text { Desenho do processo } \\
\text { básico; desenho e } \\
\text { fabricação dos } \\
\text { equipamentos }\end{array}$ \\
\hline \multirow{3}{*}{$\begin{array}{l}\text { Operação } \\
\text { /Produção }\end{array}$} & $\begin{array}{l}\text { Engenharia de } \\
\text { processo }\end{array}$ & $\begin{array}{l}\text { Controle de qualidade; } \\
\text { levantamento e análise dos } \\
\text { problemas; manutenção } \\
\text { preventiva; assimilação de } \\
\text { processo tecnológico }\end{array}$ & $\begin{array}{l}\text { Redução de custos; } \\
\text { modificação de novas } \\
\text { tecnologias de processo; } \\
\text { adaptação de processo ao novo } \\
\text { produto; melhoria na } \\
\text { qualidade dos produtos }\end{array}$ & $\begin{array}{l}\text { Inovação própria de } \\
\text { processo em departamento } \\
\text { de P\&D (Pesquisa e } \\
\text { Desenvolvimento) }\end{array}$ \\
\hline & $\begin{array}{l}\text { Engenharia de } \\
\text { produto }\end{array}$ & $\begin{array}{l}\text { Engenharia reversa; pequenas } \\
\text { adaptações às necessidades do } \\
\text { mercado }\end{array}$ & $\begin{array}{l}\text { Modificação de produtos } \\
\text { adquiridos por licenciamento }\end{array}$ & $\begin{array}{l}\text { Inovação própria de } \\
\text { produto em departamento } \\
\text { de P\&D }\end{array}$ \\
\hline & Gestão industrial & $\begin{array}{l}\text { Estudo geral dos métodos e } \\
\text { dos tempos de trabalho; } \\
\text { controle de estoques }\end{array}$ & $\begin{array}{l}\text { Monitoramento da } \\
\text { produtividade; coordenação } \\
\text { melhorada }\end{array}$ & $\begin{array}{l}\text { Venda de pacotes } \\
\text { tecnológicos ou } \\
\text { licenciamento de } \\
\text { tecnologia para terceiros }\end{array}$ \\
\hline Inovação & $\begin{array}{l}\text { Capacidade de } \\
\text { buscar inovações de } \\
\text { produto e processo } \\
\text { e de desenvolver } \\
\text { P\&D }\end{array}$ & $\begin{array}{l}\text { Conhecimento minimo sobre a } \\
\text { tecnologia em uso, necessária } \\
\text { para as empresas se manterem } \\
\text { no mercado }\end{array}$ & $\begin{array}{l}\text { Conhecimentos científicos, } \\
\text { pessoal qualificado e algum } \\
\text { direcionamento para P\&D }\end{array}$ & $\begin{array}{l}\text { Com forte aparato de } \\
\text { P\&D; procura criar/deter } \\
\text { novas tecnologias }\end{array}$ \\
\hline $\begin{array}{l}\text { Relações } \\
\text { com a } \\
\text { economia }\end{array}$ & $\begin{array}{l}\text { Inserção no } \\
\text { ambiente } \\
\text { organizacional e } \\
\text { institucional }\end{array}$ & $\begin{array}{l}\text { Obtenção de bens e serviços } \\
\text { locais; troca de informações } \\
\text { com fornecedores; cooperação, } \\
\text { alianças, afiliações em nível } \\
\text { básico }\end{array}$ & $\begin{array}{l}\text { Projetos realizados com } \\
\text { clientes e fornecedores; } \\
\text { ligações com instituições de } \\
\text { C\&T (Ciência \& Tecnol ogia); } \\
\text { cooperação, alianças, } \\
\text { afiliações em nivel } \\
\text { intermediário }\end{array}$ & $\begin{array}{l}\text { P\&D cooperativo; venda } \\
\text { de pacotes tecnológicos } \\
\text { ou licenciamento de } \\
\text { tecnologia para terceiros; } \\
\text { cooperação, alianças, } \\
\text { afiliações em nível } \\
\text { avançado }\end{array}$ \\
\hline
\end{tabular}

Figura 1 - Matriz de capacidades tecnológicas

Fonte: Lall (1992).

Em vista do exposto na Figura 1, a capacidade básica é aquela que requer o conhecimento mínimo sobre a tecnologia em uso, necessária para as empresas manterem-se no mercado. A capacidade intermediária já exige certa melhoria da tecnologia vigente (em termos gerais, em um patamar acima do observado no nível básico). Para tanto, são necessários: pessoal qualificado, conhecimentos científicos selecionados, coordenação melhorada e algum tipo de direcionamento para pesquisa e desenvolvimento (P\&D). Já a capacidade avançada, além de demandar a melhoria da tecnologia comumente em uso (em termos gerais, em um nível acima do observado no intermediário), volta-se, também, para a criação de novas tecnologias, posicionando a empresa entre as inovadoras, permitindo o aproveitamento das vantagens de agir primeiro. É a excelência que o setor possui em termos de modernização, uma vez que procura criar/deter novas tecnologias. 
Sobre a matriz de capacidades tecnológicas Lall (1992) complementa que:

The functions set out in Box 1 may not be exhaustive, and not all of them have to be performed for every industrial venture. Even where they are performed, moreover, not all need be undertaken by the firm itself - several specialized services can be brought in from (domestic or foreign) contractors, consultants or other manufacturing firms. Yet there is a basic core of functions in each major category that have to be internalized by the firm to ensure successful commercial operation (LALL, 1992, p.3).

Os âmbitos das capacidades tecnológicas também permitem uma boa interface com a questão da dinâmica tecnológica. Nesse caso, as atividades da firma são divididas em quatro, não estanques entre si, sendo: âmbito dos investimentos (perfil inicial e execução de projetos); âmbito da operação/produção (perfil engenharia de processo, engenharia de produto, gestão industrial); âmbito da inovação (capacidade de buscar inovações de produto e de processo, além de desenvolver P\&D) e âmbito de relacionamento com a economia (inserção no ambiente organizacional e institucional).

\subsection{Referencial Analítico}

O questionário aplicado (vide Apêndice), respondido pela diretoria das unidades pesquisadas (com foco na área indagada), baseou-se na matriz exposta na Figura 1. Esse tipo de pesquisa “[...] tem por objetivo a coleta 
de elementos não disponíveis, que, ordenados sistematicamente, de acordo com processos adequados, possibilitam o conhecimento de uma determinada situação, hipótese ou norma de procedimento [...]" (MUNHOZ, 1989). Em virtude de especificidades da agroindústria canavieira (porte, se produz açúcar e álcool - usina com destilaria anexa -, ou somente álcool - destilaria autônoma), a amostragem foi não probabilística e por acessibilidade (SOUZA et al., 2005; GIL, 1999). ${ }^{5}$ Foram, contudo, pesquisadas empresas de vários portes para abranger o universo de análise, ou seja, dentre os respondentes constatou-se todos os tipos de unidades estudadas (grandes, médias e pequenas); logo, além de uma representatividade numérica, houve, também, representatividade das características típicas das usinas/destilarias existentes em Minas Gerais. Isso significa que a amostra obtida tem as mesmas características que a população analisada.

Ademais, este trabalho caracteriza-se como uma pesquisa aplicada, pois o "[...] investigador é movido pela necessidade de contribuir para fins práticos e imediatos, buscando soluções para problemas concretos [...]" (CERVO e BERVIAN, 1996, p. 47). Assim, este tipo de pesquisa voltase para a aplicação, interessando-se pela utilização e consequencias práticas dos conhecimentos científicos, leis e teorias, contribuindo para a aplicação do conhecimento pelas empresas e pelo Estado. Quanto ao seu objetivo, este estudo pode ser considerado como de natureza explicativa, pois a sua principal preocupação é "[...] identificar os fatores que determinam ou que contribuem para a ocorrência dos fenômenos [...]" (GIL, 1999), aprofundando-se no conhecimento da realidade.

Para contemplar o escopo desta pesquisa, os dados primários pertinentes às capacidades tecnológicas das usinas/destilarias foram coletados no primeiro semestre de 2009, por intermédio de pesquisa de campo, via técnica de interrogação mediante a aplicação de questionários em uma reunião do Siamig/Sindaçúcar-MG e complementados por formulário respondidos via eletrônica (e-mail).

Esse tipo de pesquisa evidenciou, de certa forma, informações de caráter estratégico e/ou política de trabalho da usina/destilaria. Nesse pormenor, algumas unidades não puderam contribuir com as informações solicitadas. Por esse motivo, a amostragem supracitada foi do tipo não probabilística e por acessibilidade. 


\section{Resultados}

Em Minas Gerais, das 40 unidades pesquisadas (filiadas ao Siamig/ Sindaçúcar-MG, em operação), 35\% (amostra obtida) responderam o questionário aplicado.

Tal percentual de respostas pode ser considerado representativo do universo estudado, mesmo diante da pouca receptividade dos empresários da agroindústria canavieira em responderem questões que, para alguns, pode expor dados que denotam características de seu perfil competitivo. Entretanto, essa amostra tem as mesmas características do universo estudado por reproduzir aspectos das unidades mineiras evidenciadas em outros estudos, como, por exemplo, Shikida (1997) e Hersen et al. (2008).

A Figura 2 apresenta os percentuais de ocorrências em termos da matriz de capacidades tecnológicas da agroindústria canavieira de Minas Gerais, lembrando que os quatro âmbitos citados (investimento, operação/ produção, inovação e relações com a economia) não são estanques, existindo interações dinâmicas entre os mesmos.

\begin{tabular}{|c|c|c|c|c|}
\hline \multirow{2}{*}{ Âmbitos } & \multirow{2}{*}{ Perfis } & \multicolumn{3}{|c|}{ Capacidade tecnológica } \\
\hline & & Básica & Intermediária & Avançada \\
\hline \multirow{2}{*}{ Investimento } & Inicial & 100 & 100 & - \\
\hline & Execução de projetos & 100 & 100 & 64 \\
\hline \multirow{3}{*}{$\begin{array}{l}\text { Operação/ } \\
\text { Produção }\end{array}$} & Engenharia de processo & 86 & 93 & $\mathbf{0}$ \\
\hline & Engenharia de produto & 0 & 0 & $\mathbf{0}$ \\
\hline & Gestão industrial & 93 & 79 & $\mathbf{0}$ \\
\hline Inovação & $\begin{array}{l}\text { Capacidade de buscar } \\
\text { inovações } \\
\text { de produto e processo e } \\
\text { de desenvolver P\&D }\end{array}$ & 100 & 14 & $\mathbf{0}$ \\
\hline $\begin{array}{l}\text { Relações com } \\
\text { a economia }\end{array}$ & $\begin{array}{l}\text { Inserção no ambiente } \\
\text { organizacional } \\
\text { e institucional }\end{array}$ & 100 & 79 & $\mathbf{0}$ \\
\hline
\end{tabular}

Figura 2 - Matriz de capacidades tecnológicas da agroindústria canavieira de Minas Gerais, segundo percentual de ocorrências

Fonte: Dados da Pesquisa. 
Pery Francisco Assis Shikida, Paulo Furquim de Azevedo \&

Carlos Eduardo de Freitas Vian

Observa-se que $100 \%$ das unidades pesquisadas em Minas Gerais possuem capacidades tecnológicas para a realização de investimentos iniciais no estágio intermediário, dominando, também, o básico. Dessa forma, as usinas/destilarias, quando da realização de um investimento inicial qualquer, fundamentam-se no estudo de viabilidade técnicoeconômica, seleção do local e cronograma de investimentos, negociação de contratos com fornecedores e consultas a sistemas de informação. Essa perspectiva já era esperada em função da contribuição de investimentos iniciais feitos em uma agroindústria canavieira, que exige uma monta considerável de recursos (seja próprio ou de terceiro) e, por consequência, um criterioso plano de investimento. Como menção, citase Carvalho (2007), pois esse ressalta que uma usina padrão construída pela Dedini (SP) "[...] custa cerca de 250 milhões de reais e consiste numa estrutura formada por mais de 8 mil toneladas de equipamentos, capaz de moer 2 milhões de toneladas de cana [...]. Para produzir uma estrutura monumental como essa, são necessários 18 meses". Além disso, deve ser considerada a parte agrícola (terra) onde será cultivada, em escala, cana suficiente para a produção de dois milhões de toneladas de matéria-prima (quantidade que demanda, aproximadamente, 24.000 hectares de área).

Quanto à execução de projetos, uma vez que as plantas industriais são construídas, geralmente, por fornecedores de bens de capital, novamente $100 \%$ das unidades pesquisadas dominam o estágio básico dessa capacidade tecnológica. Tal resultado revela a importância dessa indústria na capacitação tecnológica da agroindústria canavieira, um dos elementos que explica a elevada competitividade deste setor.

Ainda no âmbito da execução de projetos, $64 \%$ dos respondentes assinalaram capacidades tecnológicas para a gradação avançada (que apresenta desenho do processo, desenho e fabricação dos equipamentos), revelando que algumas unidades se diferenciam das demais, pois procuram elas mesmas efetuarem o desenho de algumas rotinas e fabricações pontuais de equipamentos específicos. De acordo com um dos pesquisados, essa procura pelo desenho e fabricação própria destina-se 
à adequação dos projetos, considerando que a realidade vivida pela unidade produtiva muitas vezes demanda soluções ditas "caseiras", que dependem da localização das usinas, da existência de fornecedores de peças na região. Vian (2003) mostra que usinas em regiões mais distantes tendem a desenvolver a capacidade de manutenção e correções nos equipamentos/processos para não ficarem paradas muito tempo.

Em termos de seleção do melhor fornecedor de equipamentos, recrutamento e treinamento de pessoal qualificado e engenharia detalhada (o que perfaz características do nível de gradação intermediário), também houve o percentual de respostas de $100 \%$ para Minas Gerais.

No âmbito da operação/produção, perfil engenharia de processo (que tem como foco a análise dos processos da organização), verifica-se uma heterogeneidade em termos de capacidades tecnológicas, com $86 \%$ da gradação básica (controle de qualidade, levantamento e análise dos problemas, manutenção preventiva e assimilação de processo tecnológico); $93 \%$ dos respondentes no estágio intermediário (que diz respeito à redução de custos, modificação de novas tecnologias de processo, adaptação de processo aos novos produtos e melhoria na qualidade dos produtos) e nenhuma unidade mineira pesquisada figura no nível avançado (que compreende a inovação própria de processo em departamento de P\&D).

Dando sequência à análise das capacidades tecnológicas, quanto à engenharia de produto (que tem como foco o ciclo de vida do produto, formação de preço, análise da concorrência, estratégia de comercialização e divulgação do produto), percebe-se que a engenharia reversa e pequenas adaptações às necessidades do mercado, bem como modificação de produtos adquiridos por licenciamento e inovação própria de produto em departamento de $\mathrm{P} \& D$ são práticas não comuns nessa atividade em Minas Gerais.

O que fica evidente com os perfis de engenharia de processo e de produto, nos níveis básico e intermediário, é que as unidades pesquisadas enfatizam mais a engenharia de processo, no âmbito da operação/produção, do que 
Pery Francisco Assis Shikida, Paulo Furquim de Azevedo \&

Carlos Eduardo de Freitas Vian

a de produto. Isso está relacionado ao fato de que os dois principais produtos da agroindústria canavieira, o açúcar e o álcool, apresentarem maiores oportunidades de ganho em redução de custos. Isso acontece devido às melhorias no processo de produção e não da diferenciação de produto, dadas as características da demanda (que se fundamenta em características intrínsecas e objetivas desses produtos). Dessa forma, em decorrência da homogeneidade das commodities açúcar e álcool, é incomum a concorrência por diferenciação de produtos na indústria canavieira.

Quanto à gestão industrial, novamente não houve nenhuma evidência empírica para a gradação avançada, revelando que a venda de pacotes tecnológicos ou licenciamento de tecnologia para terceiros é uma prática incomum neste setor em terras mineiras. Entretanto, 93\% dos respondentes do estado apresentam capacidades tecnológicas enquadradas no nível básico (que compreende o estudo geral dos métodos e dos tempos de trabalho e o controle de estoques) e $79 \%$ figuram no nível intermediário (que se refere ao monitoramento da produtividade e à coordenação melhorada).

No âmbito da inovação, nota-se que $100 \%$ das usinas/destilarias pesquisadas em Minas Gerais estão com capacidades tecnológicas de nível básico, que se refere ao conhecimento mínimo sobre a tecnologia em uso, necessário para as empresas se manterem no mercado. No nível intermediário (conhecimentos científicos, pessoal qualificado e algum direcionamento para $\mathrm{P} \& \mathrm{D}$ ), este percentual cai drasticamente (para 14\%), sendo que nenhuma unidade mineira está inserida no âmbito da inovação na gradação avançada.

No tocante às relações com a economia, percebe-se uma nota comum para esta matriz: as usinas/destilarias pesquisadas diminuem seus percentuais de ocorrência à medida que as gradações avançam do nível básico para o intermediário e deste para o avançado. As maiores evidências de capacidades tecnológicas para este âmbito englobam obtenção de bens e serviços locais, troca de informações com 
fornecedores, cooperação, alianças e afiliações em nível básico (sendo inexistente o P\&D cooperativo), venda de pacotes tecnológicos ou licenciamento de tecnologia para terceiros, cooperação, alianças e afiliações em nível avançado. Destacam-se as citações de ligações com o Centro de Tecnologia Canavieira no que tange as instituições de Ciência \& Tecnologia (C\&T), afiliações em nível intermediário (79\%).

No ambiente organizacional e institucional da cana-de-açúcar, existe em Minas Gerais, e em alguns estados, uma associação civil sem fins lucrativos, o Conselho dos Produtores de Cana-de-Açúcar, Açúcar e Álcool (CONSECANA), regido por estatuto e regulamentos próprios, cujo intuito é divulgar, mensalmente, valores de referência do preço da tonelada de cana-de-açúcar e da participação do custo de reposição desta nos seus produtos finais. Em função do setor ser bastante influenciado pelo sistema CONSECANA, os conflitos resultantes da remuneração dessa matéria-prima são minimizados. Neves e Conejero (2007) apontam como um dos pontos fortes do sistema agroindustrial da cana a coordenação do CONSECANA.

O estado de Minas Gerais, por meio do Siamig/Sindaçúcar tem feito um trabalho importante visando ampliar a interação entre os fornecedores e os empresários das usinas/destilarias, além da coordenação da defesa dos interesses do setor. Tal perspectiva corrobora o que Shikida e Frantz (2002) dizem para o caso das relações cooperativas experimentadas por algumas agroindústrias canavieiras, sendo válida "[...] a máxima de que ações coletivas, devidamente coordenadas, possuem uma força maior que cada ação tomada isoladamente". As usinas e destilarias mineiras, mesmo concorrentes em determinados momentos, sabem se aliar para obter vantagens coletivas que dificilmente seriam conseguidas com ações isoladas. Outro aspecto dessa peculiaridade são os encontros de caráter multidisciplinar promovidos pela entidade de classe ligada ao setor, que abrangem todo o processo da cadeia produtiva da agroindústria canavieira, procurando promover a atualização de conhecimentos de técnicas e de sistemas, permitindo o reconhecimento de novas tecnologias de exploração e perspectivas, visando à melhoria de rendimento e qualidade 
Pery Francisco Assis Shikida, Paulo Furquim de Azevedo \&

Carlos Eduardo de Freitas Vian

da produção, bem como a troca de informações com fornecedores e clientes.

Destaca-se, pelo exposto, que a agroindústria canavieira em Minas Gerais domina uma parcela das capacidades tecnológicas dos níveis básico e intermediário (vide área hachurada da Figura 2). Algumas lacunas, como o âmbito da operação/produção, perfil engenharia de produto, mostram que a engenharia reversa e as pequenas adaptações às necessidades do mercado, bem como a modificação de produtos adquiridos por licenciamento e inovação própria em departamento de $\mathrm{P} \& \mathrm{D}$, têm sido práticas não usuais no setor.

Em termos das menores ocorrências (vide valores em negrito/itálico na Figura 2), comparativamente às gradações básica, intermediária e avançada, nota-se que a categoria capacidade tecnológica avançada é a que apresenta os menores percentuais de ocorrências para os demais perfis. Shikida (1997) já havia apontado que o desenvolvimento das capacidades tecnológicas foi aguçado somente com a desregulamentação, razão para esses percentuais, na atualidade, serem ainda baixos para a gradação avançada.

Contudo, esta análise permite projetar os desafios em termos de capacidades tecnológicas que a agroindústria canavieira, especialmente a mineira, precisa consolidar para firmar melhores estratégias concorrenciais, fundadas nos âmbitos dos investimentos, da operação/ produção, da inovação e do relacionamento com a economia. Há, portanto, espaço para avançar no desenho do processo básico, no esboço e fabricação dos equipamentos, na inovação de processo e, sobretudo, em $\mathrm{P} \& \mathrm{D}$, que permita não só avanço em novas tecnologias, mas seu patenteamento e venda para terceiros.

De acordo com Neves e Conejero (2007), no ambiente tecnológico, as oportunidades do sistema agroindustrial da cana são várias: mecanização da colheita; fabricação de etanol, a partir da palha e bagaço; uso de satélites e agricultura de precisão; modificação genética e novas variedades. Além disso, é preciso: 
[...] garantir o patenteamento internacional da tecnologia de produção do álcool brasileiro, para evitar a "livre importação" de tecnologia e capturar valor em cima das exportações de tecnologia $e$ posteriormente, de royalties. [...] Atividades integradas de $P \& D$ para o setor: estimular a formação de parcerias público-privadas (PPPs) e parques tecnológicos entre Embrapa, institutos agronômicos, centros de excelência nas universidades, empresas privadas, centros de tecnologia (como o CTC) e associações, com incentivos fiscais $e$ aporte de recursos para o desenvolvimento de pesquisas conjuntas do setor (NEVES e CONEJERO, 2007, p.599).

Em Minas Gerais, coexistem usinas/destilarias com distintas gradações de capacidades tecnológicas. Pelo cenário observado, verifica-se que, embora haja lacuna para crescimento em termos de melhores técnicas, a assimilação de um paradigma tecnológico como modelo de sobrevivência neste setor é cada vez mais importante no atual contexto de desregulamentação setorial, haja vista a minimização de custos, do desenvolvimento de best-practices e do aproveitamento cada vez mais intensivo de antigos e novos subprodutos. Quem se concentra nesse paradigma tecnológico, diferencia-se dos congêneres com atributos que garantirão melhores desempenhos no mercado. 


\section{Conclusão}

A aplicação empírica da matriz de Lall (1992), para a agroindústria canavieira mineira, permite concluir que essa condição é dada, fundamentalmente, pelo razoável domínio de suas capacidades tecnológicas básica e intermediária. A caracterização/gradação avançada, que é a tecnologia de ponta de um setor, ainda tem espaço para avançar. Assim, buscar excelência na capacidade tecnológica avançada certamente possibilitará vantagens competitivas adicionais para as usinas/destilarias mineiras.

Em termos de políticas públicas, tornam-se necessárias ações voltadas para fomentar a $\mathrm{P} \& \mathrm{D}$, difundir as tecnologias já comerciais e estimular a melhoria da gestão industrial (com venda de pacotes tecnológicos para terceiros). Como consequência, o melhoramento genético da cana-deaçúcar, de técnicas de fermentação e de extração industrial são exemplos de ações, referentes à ampliação dessas capacidades tecnológicas superiores e que devem resultar na consolidação da competitividade da agroindústria canavieira. Embora as usinas/destilarias estejam mais orientadas para a engenharia de processo, a de produto (resultando em diversificação da produção), é também uma estratégia corrente, com destaque para as pesquisas com o new sugar, o plástico biodegradável e o álcool lignocelulósico oriundos da cana. 


\section{Referências}

ALVES, L. R. A. 2002. Transmissão de preços entre produtores do setor sucroalcooleiro do Estado de São Paulo. Dissertação de Mestrado em Economia Aplicada. Escola Superior de Agricultura "Luiz de Queiroz" - USP. Piracicaba, SP. Brasil.

CANUTO, O. Ciclos de vida do produto e vantagens de internacionalização de capacidades tecnológicas, sob uma abordagem evolucionista. In: ENCONTRO NACIONAL DE ECONOMIA, 19., 1991, Curitiba. Anais... Brasília: ANPEC, 1991. p. 313-334.

CARVALHO, D. A fábrica de usinas. 2007. Disponível em: <http:// portalexame.abril.com.br/revista/exame/edicoes/0890/negocios/ m0125977.html.> Acesso em: 19 mar. 2010.

CERVO, A. L.; BERVIAN, P. A. Metodologia científica. 4. ed. São Paulo: Makron Books, 1996.

COMPANHIA NACIONAL DE ABASTECIMENTO (CONAB). $\mathbf{1}^{\mathbf{0}}$ Levantamento de cana-de-açúcar - abril/2010. Disponível em: <http://www.conab.gov.br/conabweb/>. Acesso em: 22 jun. 2010.

DAHLMAN, C.; ROSS-LARSON, B.; WESTPHAL, L. Managing technological development - lessons from the newly industrializing countries. Washington: World Bank Staff - Working Papers, 1985.

DOSI, G. Technical change and industrial transformation. New York: St. Martin's Press, 1984.

DOSI, G.; CORIAT, B. The nature and accumulation of organizational competences/capabilities. Revista Brasileira de Inovação, Rio de Janeiro, v.1, n.2, p.275-326, jul./dez. 2002.

GIL, A. C. Métodos e técnicas de pesquisa social. 5. ed. São Paulo: Atlas, 1999. 
Pery Francisco Assis Shikida, Paulo Furquim de Azevedo \&

Carlos Eduardo de Freitas Vian

GOES, T.; MARRA, R.; SILVA, G. S. Setor sucroalcooleiro no Brasil: situação atual e perspectivas. Revista de Política Agrícola, Brasília, ano XVII, n.2, p.39-51, abr./mai.jun., 2008.

HAGUENAUER, L.; FERRAZ, J. C.; KUPFER, D. Competição e internacionalização na indústria brasileira. In: BAUMAN, R. (Org.). O Brasil e a economia global. 3. ed. Rio de Janeiro: Campus/SOBEET, p.195-217, 1996.

HERSEN, A.; SHIKIDA, P. F. A.; DAHMER, V. de S. Concentração na agroindústria canavieira mineira pós-desregulamentação setorial. In: CONGRESSO BRASILEIRO DE ECONOMIA, ADMINISTRAÇÃO E SOCIOLOGIA RURAL, 46. Rio Branco - AC, 2008. Anais... Rio Branco: SOBER/UFAC, 2008.

KUPFER, D. Uma abordagem neo-schumpeteriana da competitividade industrial. Revista Ensaios FEE, Porto Alegre, v.17, n.01. p.355-372, 1996.

LALL, S. Technological capabilities and industrialization. World Development, v.2, n.20, p.165-186, february, 1992. Disponível em: <http:/ /www.unu.edu/unupress/unupbooks/>. Acesso em: 01 mar. 2010.

MATESCO, V. R. Atividade tecnológica das empresas brasileiras: desempenho e motivação para inovar. In.: Perspectiva da economia brasileira 1994. Rio de Janeiro: IPEA, v.1, p.397-419, 1994.

MUNHOZ, D. G. Economia aplicada: técnicas de pesquisa e análise econômica. Brasília: Editora Universidade de Brasília, 1989. 300 p.

NEVES, M. F.; CONEJERO, M. A. Sistema agroindustrial da cana: cenários e agenda estratégica. Revista de Economia Aplicada, Ribeirão Preto, v.11, n.4, p.587-604, out./dez., 2007. 
PAULILLO, L. F.; VIAN, C. E. de F.; SHIKIDA, P. F. A.; MELLO, F. T. de. Álcool combustível e biodiesel no Brasil: quo vadis? Revista de Economia e Sociologia Rural, Brasília, v.45, n.03. p.531-565, jul./set., 2007.

POSSAS, M. L. Concorrência, inovação e complexos industriais: algumas questões conceituais. Cadernos de Ciência \& Tecnologia, Brasília, v.8, n.1/3, p.78-97, jan./dez. 1991.

SCHMIDTKE, C. R. et al. Expectativas da agroindústria canavieira paranaense diante da diminuição do protecionismo no comércio internacional. Revista de Economia \& Relações Internacionais, São Paulo, v.7, n.13, p.95-120, 2008.

SCHUMPETER, J. A. Capitalismo, socialismo e democracia. Rio de Janeiro: Fundo de Cultura, 1961.512 p.

SHIKIDA, P. F. A. 1997. A evolução diferenciada da agroindústria canavieira no Brasil de 1975 a 1995. Tese de ??? Escola Superior de Agricultura "Luiz de Queiroz" - USP. Piracicaba, São Paulo.

SHIKIDA, P. F. A.; FRANTZ, R. L. Estratégias de atuação da ALCOPAR (PR) em face da desregulamentação setorial e da globalização da economia. In: MONTOYA, M. A.; ROSSETO, C. R. (Org.); Abertura econômica e competitividade no agronegócio brasileiro: impactos regionais e gestão estratégica. Passo Fundo: UPF, 2002. p.181-205.

SINDICATO DA INDÚSTRIA DE FABRICAÇÃO DO ÁLCOOL NO ESTADO DE MINAS GERAIS/SINDICATO DA INDÚSTRIA DO AÇÚCAR NO ESTADO DE MINAS GERAIS (SIAMIG/ SINDAÇÚCAR-MG). Relatório Econômico. No 005 - Belo Horizonte/ MG - 20/01/2009. 
Pery Francisco Assis Shikida, Paulo Furquim de Azevedo \&

Carlos Eduardo de Freitas Vian

SOUZA, E. C. de; SHIKIDA, P. F. A.; MARTINS, J. P. Uma análise da agroindústria canavieira do Paraná à guisa da matriz de capacidades tecnológicas. Revista de Economia e Agronegócio. Viçosa, v.3, n.3, p.349-375, jul./set. 2005.

SOUZA, E. L. de; MACEDO, I. de C. (Coord.) Etanol e bioeletricidade: a cana-de-açúcar no futuro da matriz energética. São Paulo: Luc Projetos de Comunicação, 2010. 314 p.

TIGRE, P. B. Paradigmas tecnológicos e teorias econômicas da firma. Revista Brasileira de Inovação. Rio de Janeiro, v.4, n.1, p.187-224, jan./jun. 2005.

UNIÃO DA AGROINDÚSTRIA CANAVIEIRA DE SÃO PAULO (UNICA). Estatísticas. Disponível em: <http://www.portalunica.com.br/ portalunica/>. Acesso em: 09 mar. 2010.

UNIÃO DA AGROINDÚSTRIA CANAVIEIRA DE SÃO PAULO (ÚNICA). Produção e uso do etanol combustível no Brasil: respostas às questões mais freqüentes. São Paulo: UNICA, 2007. 68 p.

VIAN, C. E. de F. Agroindústria canavieira: estratégias competitivas e modernização. Campinas: Átomo, 2003. 216 p. 


\begin{abstract}
This paper aims to appraise the technological capabilities of sugarcane agroindustry in Minas Gerais State, that has the second largest area planted with sugarcane in Brazil, that is 679.000 ha. A field research survey with sugar and ethanol mills provides the primary data for assessing technological capabilities. The theoretical approach used was the technological capabilities matrix, which is based in Lall (1992), being this matrix divided into three specifications: basic (simple routine), intermediate (adaptive duplicative) and advanced (innovative risky). As a main finding, this sugarcane agro-industry, technically qualified and with low cost, presents a reasonable domain of basic and intermediate technological capabilities. However, the advanced technological capabilities are still lagging behind the technological frontier.
\end{abstract}

Keywords: Dynamics, technology, sugar, ethanol.

\title{
APÊNDICE - Questionário Aplicado
}

1) Existe na Usina/Destilaria, quando de um INVESTIMENTO inicial qualquer, estudos de viabilidade técnica-econômica, seleção de local/ produto e/ou serviço sob rigor técnico, cronogramas de investimentos, ou seja, quesitos necessários para a efetivação segura de um investimento?
( ) $\operatorname{Sim}$
( ) Não

2) Existe na Usina/Destilaria, quando de um INVESTIMENTO inicial qualquer, negociação de contratos com fornecedores e prévio sistema de informação sobre quem são estes fornecedores e seus produtos/ serviços?
( ) $\operatorname{Sim}$
( ) Não

3) Existe na Usina/Destilaria, quando da EXECUÇÃO DE UM PROJETO qualquer, construção de plantas (que seguem um planejamento prévio)?
( ) $\operatorname{Sim}$
( ) Não 
4) Existe na Usina/Destilaria, quando da EXECUÇÃO DE UM PROJETO qualquer, seleção do melhor fornecedor de equipamentos, engenharia detalhada, recrutamento e treinamento de pessoal qualificado para executar este projeto?
( ) $\operatorname{Sim}$
( ) Não

5) Existe na Usina/Destilaria, quando da EXECUÇÃO DE UM PROJETO qualquer, desenho e fabricação dos equipamentos pela própria Usina/Destilaria?
( ) $\operatorname{Sim}$
( ) Não

6) Existe na Usina/Destilaria, quando da OPERAÇÃO/PRODUÇÃO (engenharia de processo), controle de qualidade, levantamento e análise dos problemas, manutenção preventiva, assimilação do processo tecnológico vigente no setor sucroalcooleiro?
( ) $\operatorname{Sim}$
( ) Não

7) Existe na Usina/Destilaria, quando da OPERAÇÃO/PRODUÇÃO (item engenharia de processo), política de redução de custos, modificação de novas tecnologias de processo e adaptação de processo ao novo produto, política de melhoria na qualidade dos produtos?
( ) $\operatorname{Sim}$
( ) Não

8) Existe na Usina/Destilaria, quando da OPERAÇÃO/PRODUÇÃO (item engenharia de processo), inovação própria de produto e Departamento de Pesquisa e Desenvolvimento (P\&D) na própria Usina/ Destilaria?
( ) $\operatorname{Sim}$
( ) Não 
9) Existe na Usina/Destilaria, quando da OPERAÇÃO/PRODUÇÃO (item engenharia de produto), a engenharia reversa?
( ) $\operatorname{Sim}$
( ) Não

10) Existe na Usina/Destilaria, quando da OPERAÇÃO/PRODUÇÃO (item engenharia de produto), modificação de produtos adquiridos por licenciamento?

( ) $\operatorname{Sim}$

( ) Não

11) Existe na Usina/Destilaria, quando da OPERAÇÃO/PRODUÇÃO (item engenharia de produto), inovação própria de produto em Departamento de P\&D na própria Usina/Destilaria?

( ) $\operatorname{Sim}$

( ) Não

12) Existe na Usina/Destilaria, quando da OPERAÇÃO/PRODUÇÃO (item gestão agroindustrial), o estudo geral dos métodos e dos tempos de trabalho, e controle de estoques?
( ) $\operatorname{Sim}$
( ) Não

13) Existe na Usina/Destilaria, quando da OPERAÇÃO/PRODUÇÃO (item gestão agroindustrial), o monitoramento da produtividade e a coordenação melhorada?
( ) $\operatorname{Sim}$
( ) Não

14) Existe na Usina/Destilaria, quando da OPERAÇÃO/PRODUÇÃO (item gestão agroindustrial), a venda de pacotes tecnológicos ou licenciamento de tecnologia para terceiros?
( ) $\operatorname{Sim}$
( ) Não 
15) Existe na Usina/Destilaria, quando da INOVAÇÃO, o conhecimento mínimo sobre a tecnologia em uso, necessária para a Usina/Destilaria se manter no mercado?

( ) $\operatorname{Sim}$

( ) Não

16) Existe na Usina/Destilaria, quando da INOVAÇÃO, conhecimentos científicos, pessoal qualificado e algum direcionamento para $\mathrm{P} \& \mathrm{D}$ ?

( ) $\operatorname{Sim}$

( ) Não

17) Existe na Usina/Destilaria, quando da INOVAÇÃO, forte aparato de P\&D para toda a Usina/Destilaria?

( ) $\operatorname{Sim}$

( ) Não

18) Existe na Usina/Destilaria, quando das RELAÇÕES COM A ECONOMIA, trocas de informações com fornecedores, cooperação/ alianças e/ou afiliações em nível básico (associação patronal de classes, etc, de âmbito local e/ou regional)?
( ) $\operatorname{Sim}$
( ) Não

19) Existe na Usina/Destilaria, quando das RELAÇÕES COM A ECONOMIA, projetos realizados com clientes e fornecedores, ligações com instituições de C\&T (Ciência \& Tecnologia), cooperação/alianças e/ou afiliações em nível intermediário (de âmbito nacional)?
( ) $\operatorname{Sim}$
( ) Não

20) Existe na Usina/Destilaria, quando das RELAÇÕES COM A ECONOMIA, P\&D cooperativo, venda de pacotes tecnológicos ou licenciamento de tecnologia para terceiros, cooperação/alianças e/ou afiliações em nível avançado (de âmbito nacional e internacional)?

( ) $\operatorname{Sim}$ ( ) Não 
REVISTA DE ECONOMIA E AGRONEGÓCIO, VOL.8, $N^{o} 2$ 